\title{
Conceptual framework of a Solar PV based high voltage Battery charging strategyfor PHEVs and EVs
}

\author{
Mohammad Saad Alam \\ Lead Systems Engineer- MagnetiMarelli Holdings of North America Inc (FIAT GROUP SpA)
}

Email address:

hybridvehicle@gmail.com

\section{To cite this article:}

Mohammad Saad Alam. Conceptual Framework of a Solar PV Based High Voltage Battery Charging Strategyfor PHEVs and EVs.American Journal of Electrical Power and Energy Systems. Vol. 2, No. 6, 2013, pp. 137-143.doi: 10.11648/j.epes.20130206.13

\begin{abstract}
With the emergence of plugin hybrid electric vehicles (PHEVs) and electric vehicles (EVs) in the automotive market, the rate of the demand for electric power supply may be higher than the projected level. Distributed power generation is a feasible solution to balance the demand and supply of the power industry. In this work, a conceptual model of a solar photovoltaic (PV) based distributed generation system is proposed for charging the PHEVs and EVs. Outline of the overall system is developed with details of the background and feasibility analysis through hardware in the loop experiment of the proposed strategy.
\end{abstract}

Keywords: Solar PV, Electric Vehicle, High Voltage Battery, Charger

\section{Introduction}

The electric power supply industry is being deregulated into a "competitive electricity market" wherein the power system is being allocated into competitive generating and distributing groups, which are all linked through the transmission grid [1]. The random nature of consumer demand leads to uncertainty in forecasting demand, and hitches are compounded at peak demand periods. Endeavors to balance the proportion of the power supply and demand in peak hours, strain the power system with a risk of vulnerable to most disturbances [2].The demand load on any power grid must be matched by the supply to it and its ability to transmit that power [1-3]. Peak power is required at times of day when high levels of demand are expected (e.g., hot summer afternoons with huge demand for air conditioning). On top of the peak power management, the electric power industry is expecting another challenge of meeting the charging demand of plugin hybrid (PHEV) and electric vehicles (EV) [3]. Automotive pundits are forecasting that $10-20 \%$ of vehicles on the road will be PHEVs and EVs by 2025 [4]. The contemporary establishment of the power generation is not capable of handling the charging needs of even $5 \%$ of vehicles and power demands at peak times can lead to blackouts [5-6]. Smart grid is emerging as a potential solution to manage and enhance the efficiency and reliability of the existing electric power generation, transmission and distribution set up [6]. However, Smart grid will heavily rely on micro grids to meet the peak power demands locally before rustling the power from the power distribution system [7]. The solar PV System has an appropriate output profile with the peak demand time which can be utilized to meet the charging needs of the growing numbers of PHEVs and EVs [3]. Further, in the absence of the PHEV's and EV's charging requirements, the generated power can be fed into Smart grid to further facilitate the peak power management. Implementing solar technology with the automotive industry willalso be anearnest progression towards preserving the environment. The matter of charging the batteries of the vehicle, however poses major implications for the future [8-10]. Having a solar powered charging station set up at a wide range of locations, however can change the considerations of users that are unwilling to buy a hybrid/electric car as a result of lack of affordable charging options.

The conceptual lay out of the proposed solar PV based charging station entails $6 \mathrm{~kW}$ micro grid including twenty four 240W solar panels, a compatible MPPT charge controller, a 240/210/280V inverter, and SAETM J1772 compatible Electric Vehicle Supply Equipment (EVSE). Further details will be elaborated in the following sections of the manuscript.

This paper consists of 7 sections. The background of the existing PHEVs and EVs charging principles, schemes, standards, developments and challenge will be covered in 
brief in section II. Section III and IV comprises the problem formulation and the conceptual lay out of the solar PV based charging station, respectively. Further, a case study of an on board high voltage battery charging for PHEVs and EVs through the proposed solar PV based charging strategy will be performed in section $\mathrm{V}$, followed by cost analysis in section VI. Finally, the conclusion is outlined in section VII.

\section{Background}

The Society of Automotive Engineers (SAE) in coordination with the Original Automotive Equipment Manufacturers (OEMs) and National Electrical Manufacturers Association (NEMA) have standardized two levels of charging namely Level 1 and Level 2 and SAETM J1772 as a standard for EVSE [11-12].

The Level 1 schemeis based on the conventional residential and commercial standard power supply of 120VAC, 15Amp/ $20 \mathrm{Amp}$ (12 Amp/ 16 Amp useable) and is being implemented through an extension cord scheme with an on-board charging system [11-12]. However, Level 1 charging is a time consuming method as it is capable of delivering a maximum of only $1.44 \mathrm{~kW}$. This method is not the best solution to the PHEVs and EVs charging needs but definitely is important for emergency situations as it has 'Portable Spare Tire' approach [11-12].On the other hand,
Level 1 allows interface to electrical outlets in compliance with the NEC - Article 625 [13].

Currently, the primary charging method for EVs is Level 2 which requires a 240VAC, single-phase, 40-Amp branch circuit with an on-board charging module. Level 2schematic is hard-wired to home wiring system and requires a permanent private residential installation. Level 2 charging operation can be further categorized based on the mode of charging as inductive and conductive equipment. The popular EVSEs are conductive equipment which have "pin and sleeve" type assembly [11-12]. The inductive scheme is based on the inductive transfer of energytothe high voltage battery of the vehicle without any physical contact and is meant only for EVs and not PHEVs.

For universalizing the EVSEs, SAETM J1772 standards committee facilitates the guideline forEVSEs manufactured by OEMs or their affiliated supplier companies [11-12]. EVSE can be define as aPhysical link for networking the electric power supply grid to the on-board chargers of PHEVs and EVs. SAETM J1772 endorse the hardware, electric, andoperational requirements for the conductive charging method use for PHEVs and BEVs with a comprehensive inclusion of everything that associates with the charging system [11-13]. AC Level 2 may be utilized at home, workplace, and public charging facilities. In summary, the charging schemeappropriate for usage with electrical ratings islisted in Table 1.

Table I:Charge method Electrical ratings (North America) [11-15]

\begin{tabular}{cccc}
\hline Charge Method & Supply AC Voltage (V) & Maximum Current(Amp) & Circuit Breaker rating (Amps) \\
\hline AC Level 1 & $120 \mathrm{~V}$, 1-phase & $12 \mathrm{~A} / 16 \mathrm{~A}$ & $15 \mathrm{~A}($ minimum)/20 A \\
AC Level 2 & $208-240 \mathrm{~V}$, 1-phase & $\leq 80 \mathrm{~A}$ & Per NEC 625 \\
\hline
\end{tabular}

As a counterpart of commercial gas stations, Level 3 or fast charging method isbeing installed at few locations in USA. Level 3 has an off board charging system of 60 to $150 \mathrm{kWwith}$ 480VAC, three-phase circuit with an estimated charging time of $10-20$ minutes to achieve $40-55 \%$ of the state of the charge (SOC) of the on-board high voltage battery [14-15].

\section{Emerging Need andSystem Requirements of a Charging Station}

The aim of the solar PV based charging strategy for PHEVs and EVs is to explore the potential of solar energy as an alternative and/or as a supplement to address the surge in power demand for the charging provisions of PHEVs and EVs. There exists a choice between theisolated or grid connected charging stations. From feasibility and customer's convenience perspective, a grid connected solar PV charging station is being considered in this work. However, the solar PV based PHEV and EV charging setup is modular in nature and can be implemented as an isolated entity or in conjunction with renewable or existing power generation sources as hybrid power system.

The fundamental issue to address is to predict the energy requirement of the high voltage battery bank of PHEVs and EVs, the frequency of charges, and the number of vehicles being served. For analysis purpose we are considering an exemplary electric vehicle very similar to the commercially available 2012 Nissan Leaf EV and/or 2012Chevy VoltPHEV. It is also assumed that with Level 1 charging scheme, not more than 2 vehicles will be charged from sun rise to sun set on a typical sunny day.

Before accessing the required energy by the high voltage battery pack of an EV, it is beneficial to perform the following analysis. Assuming the battery is made of 48 modules, and each module contains 4 cells; two of which are parallel, to give a total of about 345V [16-17]. The battery compounds are spinel $\mathrm{LiMn}_{2} \mathrm{O}_{4}$ that can deliver high energy density, and is cheaper and less toxic than $\mathrm{LiCoO}_{2}$ which brings the specific energy density of 140 $\mathrm{Wh} / \mathrm{kg}$ [16-17]. Further, a three minute driving cycle sample is taken at $25^{\circ} \mathrm{C}$ to get a feel for how much maximum energy would be used by the EV, assuming the vehicle is being driven by a driver weighing 200 pounds or less. The velocity of the vehicle vs. the time is plotted in 
Figure 1 and the relevant energy consumed is tabulated in Table II.

Table II: Energy Required by EV

\begin{tabular}{lll}
\hline Interval (seconds) & Energy $(\mathbf{J})$ & Energy (W-hr) \\
\hline 0 to 5 & 0 & 0 \\
5 to 11 & 229850 & 63.85 \\
11 to 23 & 66789 & 18.55 \\
23 to 27 & 428720 & 119.09 \\
27 to 87 & 995100 & 276.42 \\
87 to 102 & -27518 & -7.64 \\
102 to 107 & 0 & 0 \\
107 to 111 & 278580 & 77.38 \\
111 to 151 & 273080 & 75.86 \\
151 to 160 & -37193 & -10.33 \\
160 to 175 & 36852 & 10.24 \\
175 to 180 & -4599.7 & -1.28 \\
Total Energy & $=2239660 \mathrm{~J}$ & $=622 \mathrm{~W}-\mathrm{hr}$ \\
\hline
\end{tabular}

In forward motion, the energy used, $E_{f}$, can be calculated through equation1, assuming the average velocity over the

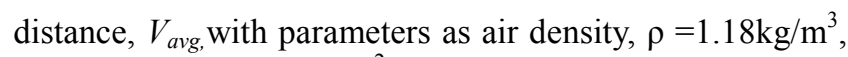
frontal area, $\mathrm{A}_{\mathrm{f}}=2.4 \mathrm{~m}^{2}$, coefficient of drag for an $A$ segment small car, $\mathrm{C}_{\mathrm{d}}=.28$ [ 16-17].

$$
E_{f}=D\left[\operatorname{sgn}\left[V_{\text {avg }}\right]\left(m g\left(C_{o}+C_{1} V_{a v g}{ }^{2}\right)+\frac{\rho}{2} C_{d} A_{f} V_{a v g}{ }^{2}\right)+m \frac{d V}{d t}\right]
$$

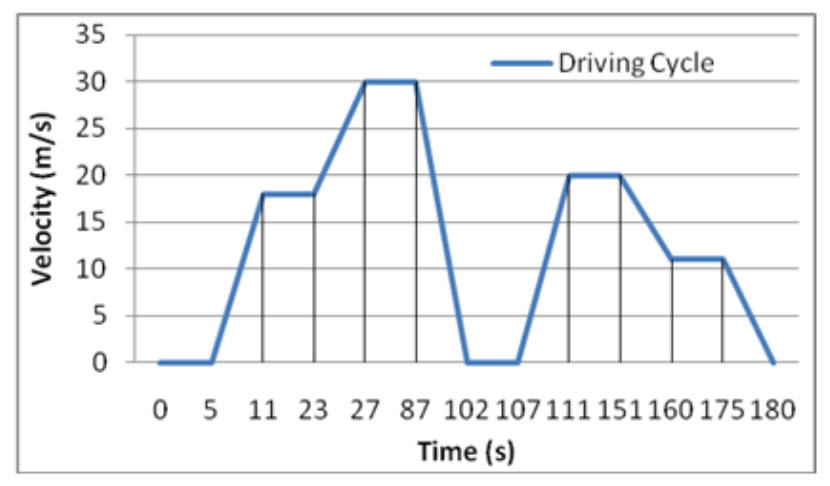

Fig. 1: The graph illustrates a short drive cycle for a span of 3 minutes.

This is a well-known fact that, what makes PHEVs and EVsexceptional is the ability to regenerate an average of approximately $30 \%$ of the energy that can be recovered during braking and can be calculated as [16-17].

$$
E_{r}(\operatorname{sgn}[\text { brakeapplied }])=.3\left(\frac{1}{2} m V_{\text {avg }}^{2}-D F_{t_{\text {avg }}}\right)(\operatorname{sgn}[\text { brakeapplied }])
$$

Where $E_{r}$ is the energy recovered in joules and $D$ is the distance EV will travel over the course of braking, and $F_{t_{a v g}}$ is the average of the total drag force minusm $\frac{d V}{d t}$.If we only consider $E_{f} \& E_{r}$ as our energy loss and gain and neglecting the other energy loss factors, with the illustrated driving cycle amplified to 30 minutes, the consumption of energy would be $6.22 \mathrm{kWh}$ used. That is only $26 \%$ of the $24 \mathrm{kWh}$ battery capacity found in the EV. The other energy consumption factors which were not included could easily have elevated the consumption to over $30 \%$ for a 30 minute drive. The highest recommended state of charge (SOC) should be around $80 \%$; thus, dropping the total capacity to around $19 \mathrm{kWh}$. Up to $80 \%$ depletion is recommended as maximum use before the EV must be recharged $(24 \mathrm{kWh} * .8$ $=19.2$ and $19.2 \mathrm{kWh} * .8=15.36 \mathrm{kWh}$ is the practical high voltage battery capacity can deliver). Moreover, to examine the maximum driving range $\mathrm{EV}$ can deliver within the safe range of battery usage (using the driving cycle example) of3788 meters $(2.35 \mathrm{miles})$ isthe total distance was covered during the trip.For $15.36 \mathrm{kWh}$ capacity $\frac{3790 \mathrm{~m}}{.622 \mathrm{kWh}}=$ $93590 \mathrm{~m} \approx 58$ miles . Note, $15.36 \mathrm{kWh} / 58 \mathrm{miles} \frac{15.36 \mathrm{kWh}}{58 \mathrm{miles}} \approx$ $264 \mathrm{Wh} / \mathrm{mile}$ Therefore, in order to reach the 100 miles range EV need $26.6 \mathrm{kWh}$ usable energy capacity.In order to realize the required energy prediction the discharging and charging power limits vs. the drivable state of the charge (SOC) is plotted for a typical EV High voltage Li-ion battery in Figure 2.Now, a charging set up is need to be developed that can address the requirement of the EV/ PHEV charging system as calculated above. A solar PV charging system is being proposed in the next section. The main charging power source will be Solar PV arrays. In case of the unavailability of the required charging power, necessary power will be pulled from the grid.

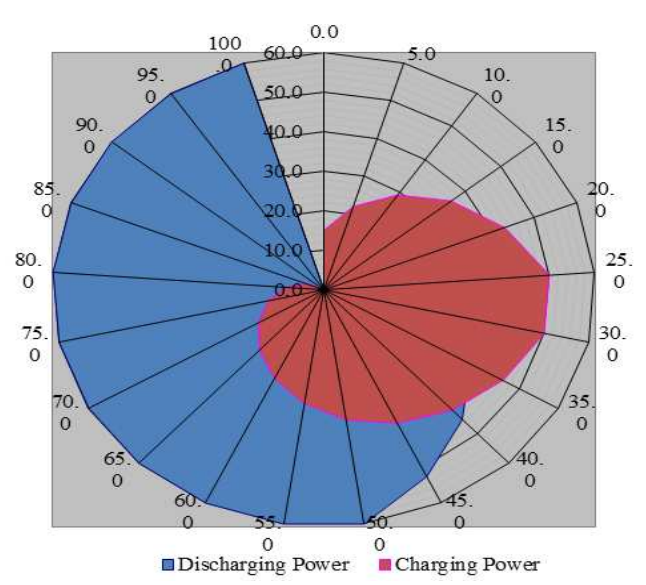

Fig. 2: Discharging and Charging Power Limits Vs State of the Charge (SOC) of the High Voltage Battery

\section{Conceptual Model of a Solar PV Based Charging Station}

In the propose charging system, DC power generated from the PV arrays will be fed to the converter and then the rectified power will be utilized to charge the High Voltage (HV) battery pack of EVs. A generic case study is performed to charge a $16 \mathrm{~kW}$-hr High voltage battery pack, very similar to commercially available PHEV like Chevy Volt [18-19]. Also, possible loads of an EV like the Nissan 
Leaf's $24 \mathrm{~kW}$-hr lithium battery were reviewed. It was assumed that the EV or PHEV being charged has not a dead battery or with $0 \% \mathrm{SOC}$ and thus, determined that this system could handle the load independently. The block diagram of the charging station is shown in Figure 3.

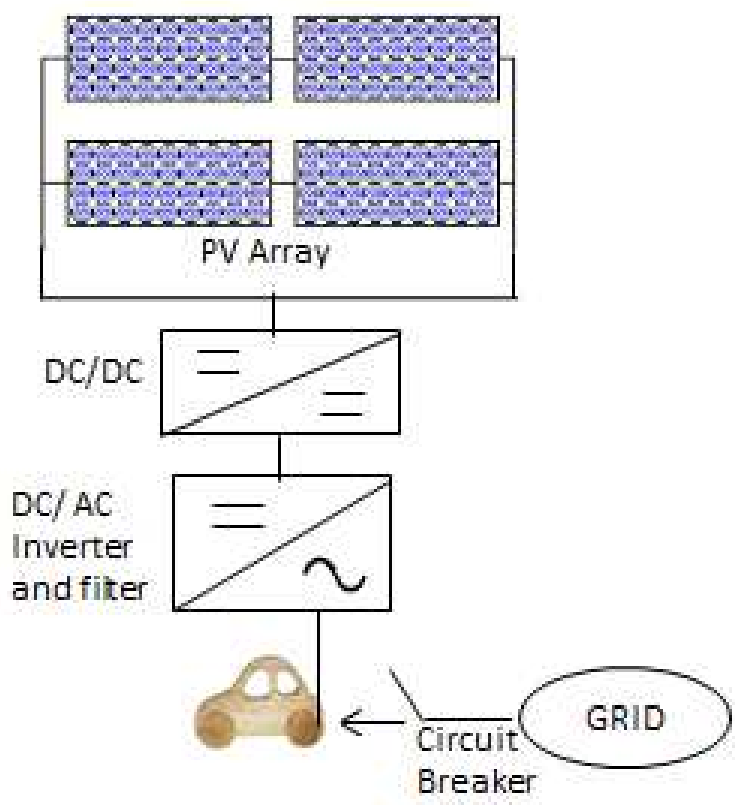

Fig. 3: Block diagram of the proposed PV based EV charging model

The EV/PHEV charge process should start as per the sequence described in the following flow chart of Figure 4.

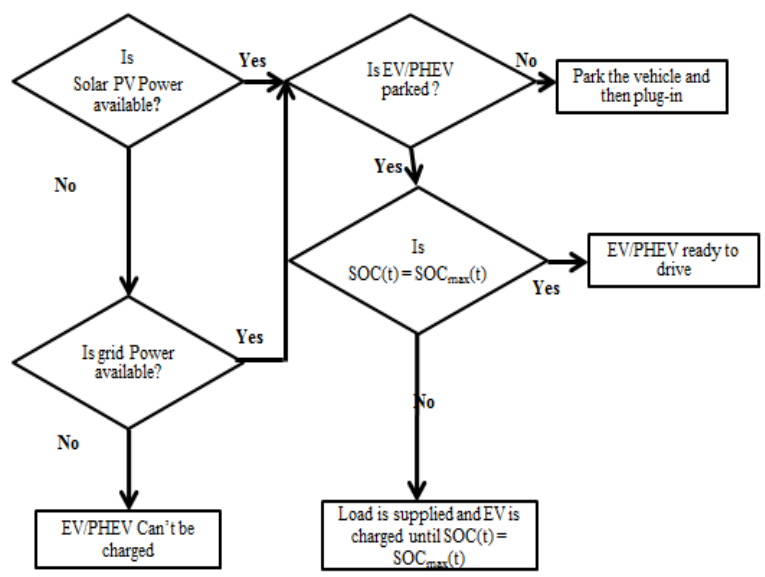

Fig. 4: Flow chart outlining the overview of the PHEV/EV charging sequence.

After the EV/PHEV is parked, the Solar PV power or the power from the grid in case of the unavailability of the power from Solar PV arrays like during night time will charge the high voltage battery till the SOC reached to its maximum value or the person unplugged the EVSE. To analyze the proposed lay out a case study is performed and reported in the next section.

\section{Case Study ofHV Battery Charging For PHEVs and EVs}

For a parking lot location in Michigan, USA, the annual solar radiation profile obtained through weather data analysis[20-22]is plotted in Figure 5 and the daily solar irradiance for a typical day of June is plotted in Figure 6.

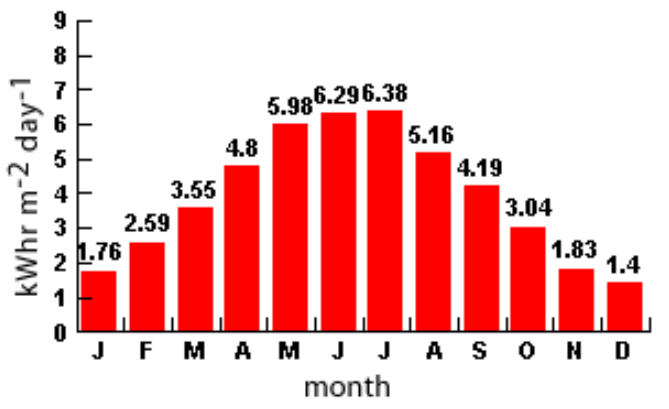

Fig.5: Annual Solar radiation profile [20-21]

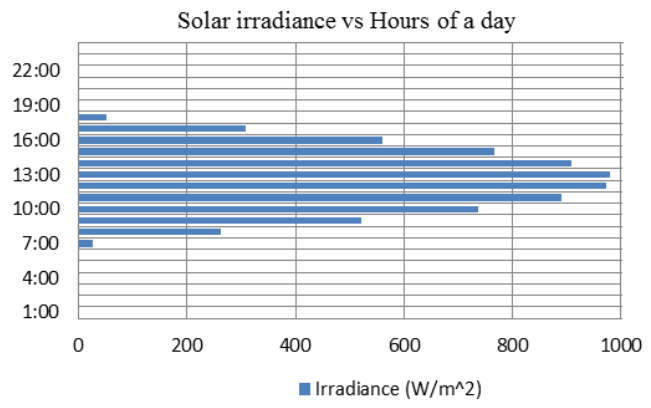

Fig. 6:Daily solar radiation profile on a typical day of June 2012 [21-22]

Installing the Solar PV system at an appropriate location is a key factor in determining the output efficiency. It isevident from Figure 6 that the operational solar irradiance is available between $9 \mathrm{AM}-4 \mathrm{PM}$. Also, as Level1 charge takes 6-7 hours for $50 \%$ SOC for a typical EV, a convenient and optimal choice for an EV charging station would be the parking lot of the driver's work place. The charging set up in the parking lot should be free from tree or building shadows and the panels must be installed facing south with a 42.9 degree tilt angle for maximum achievable efficiency [23-25].

The optimal choice for the solar PV module is achieved through a compromise on the cost and the requirement and Trina Solar TMS-240PA05 modules are being selected for the proposed charging set up [26]. These modules consists of $240 \mathrm{~W}$ panel, with a maximum voltage and current of $30.6 \mathrm{~V}$ and $7.84 \mathrm{Amps}$ respectively with claimed module efficiency of $14.7 \%$. The Parameters of TMS-240PA05 are tabulated in Table III [26] and the I-V curve is plotted in Figure 7.

Compatible MPPT charge controllers are being installed for achieving maximum power efficiency and two arrays are being designed with 12 modules in each array.The selected inverters areFronius IG Plus 11.4-1 UNI inverters [27]. These inverters have efficiency of $96.2 \%$. The inverters have a Maximum Power Point Tracking input 
voltage range of $230-500 \mathrm{Vdc}$, a nominal input current of 31.4Amp. The output has a $60 \mathrm{~Hz}$ nominal frequency output, with a THD of $<3 \%$, and an output power factor of 1. Rest of the required electrical components selected for the charging set up are NEC approved and the charging setup meet the entire local, state and federal safety codes.

Table III: Parameters for TMS-240PA05 PV Module

\begin{tabular}{ll}
\hline Parameter & Values \\
\hline Peak Power Watts- $\mathrm{P}_{\text {MAX }}(\mathrm{W})$ & 240 \\
Power output Tolerance (\%) & $0 /+3$ \\
Maximum Power Voltage- $\mathrm{V}_{\mathrm{MPP}}(\mathrm{V})$ & 30.6 \\
Maximum Power Current- $\mathrm{I}_{\mathrm{MPP}}(\mathrm{A})$ & 7.84 \\
Open Circuit Voltage- $\mathrm{V}_{\mathrm{OC}}(\mathrm{V})$ & 37.5 \\
Short Circuit Current- $\mathrm{I}_{\mathrm{sc}}(\mathrm{A})$ & 8.38 \\
Temperature Coefficient of $\mathrm{P}_{\mathrm{MAX}}(\%)$ & $-0.45 \% /{ }^{0} \mathrm{C}$ \\
Temperature Coefficient of $\mathrm{V}_{\mathrm{OC}}(\%)$ & $-0.35 \% /{ }^{\circ} \mathrm{C}$ \\
Temperature Coefficient of $\mathrm{I}_{\mathrm{sc}}(\%)$ & $0.05 \% /{ }^{\circ} \mathrm{C}$ \\
\hline
\end{tabular}

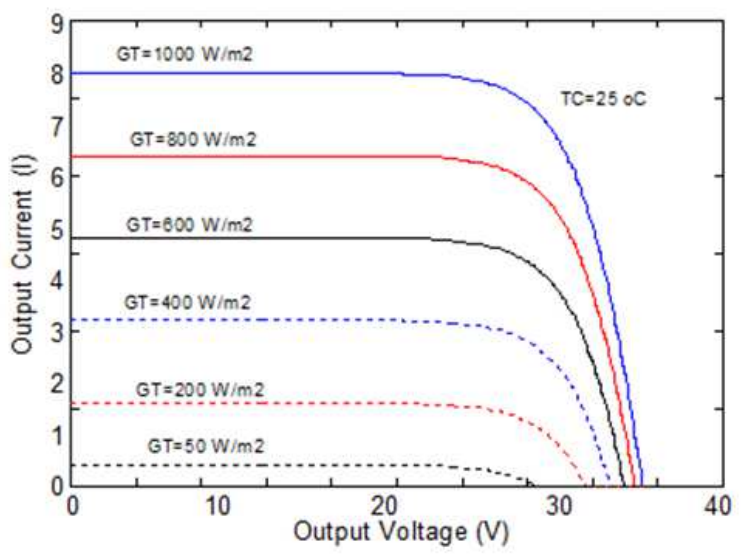

Fig. 7:I-V curves for TMS-240PA05 PV Module at $25^{\circ} \mathrm{C}$

The charging of the EV for this case study is performed through hardware in the loop (HIL) system and the charging process follow the steps as elaborated in the flow chart in Figure 4.

Level 1 charging set up was performed through HIL at $25^{\circ} \mathrm{C}$ ambient temperature and varying solar irradiance profile of Figure 6 plotted from real weather data. The EV is charged from an SAETM J1772 compatibleEVSE for 6 hours from 9:30 AM to 3:30 PM. The charging started at $13 \%$ SOC and at 3:30 PM, when EVSE is unplugged, observed SOC was $67 \%$, which will give an approximate 45-50 miles non-highway drive. The battery voltage, actual battery power available, battery SOC, solar PV charging current, variation in solar irradiance including clouding effect and the minimum and maximum drivable range of the EV are plotted in Figure 8. A disturbance in the middle of the charging can be observed which arise due to the switching of Air conditioning and accessories for some time to replicate a real world scenario.

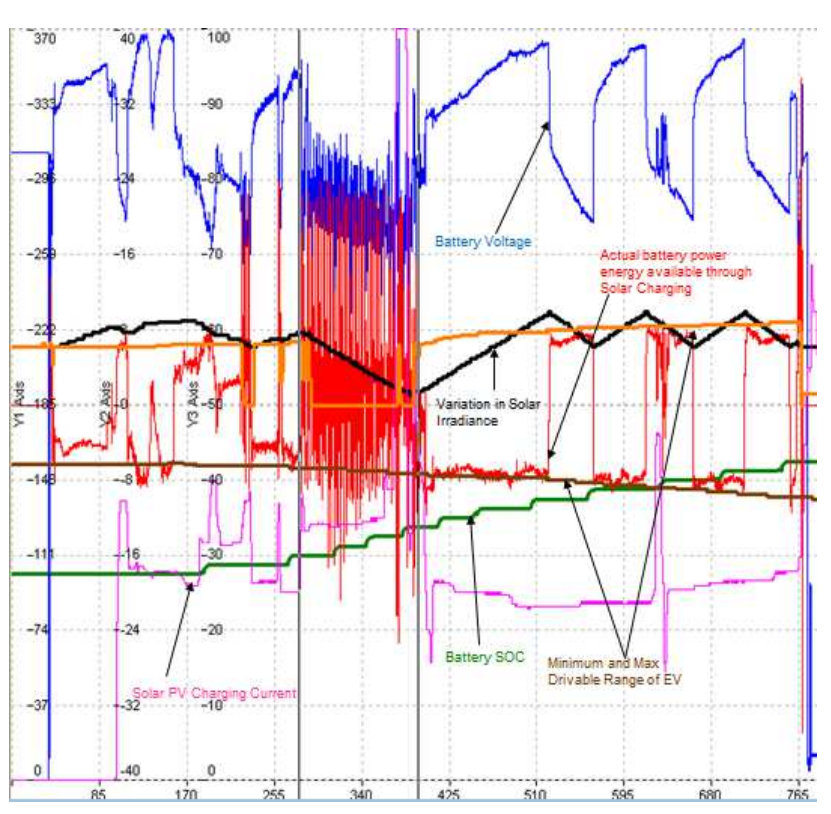

Fig. 8: Plot of solar irradiance, and various EV charging parameters

Assuming an average 40-50 miles being driven on a typical week day, the per cent contribution of the proposed solar PV charging scheme and the power drawn from the grid for EV charging for the whole year is calculated through NREL's Hybrid Optimization Model for Electric Renewables [28] tool and the available average annual solar irradiance (as plotted in Figure 5) tabulated in Table III. For a single EV/PHEV, the proposed solar PV charging schemes is capable of providing $76 \%$ of the charging demand. This is a significant achievement though at high initial setup cost. The cost analysis, payback period and gain margin is presented in the next section.

Table IV: Power production from Solar PV and power pulled from grid.

\begin{tabular}{lll}
\hline Charging & $\mathbf{k W h} / \mathbf{y r}$ & \% provision \\
\hline Solar PV System & 7567 & 76 \\
Grid & 2389 & 24 \\
Total & 9956 & 100 \\
\hline
\end{tabular}

\section{Cost analysis}

The total solar PV charging system cost includes the 24 solar PV modules; two grid tied inverter, 24 MPPT charge controllers, supplies, mounting racks, and setup costs. The initial cost of the system is approximately $\$ 19,560$, reduced to $\$ 13,692$ due to a $30 \%$ incentive. The incentive amountwill be a rebate from Consumers Energy's "Experimental Advanced Renewable" program [29]. With a 12 year contract, through this program, the commercial suppliers can be paid $\$ 0.45 / \mathrm{kWh}$ or $\$ 0.375 / \mathrm{kWh}$. A rate of 10 cents per Kilowatt hour with $2 \%$ inflation for the next 20 years is computed. RET-Screen $\AA[30]$ was used to analyze the overall cost of the proposedsolar PV charging system and the estimated payback period is plotted in Figure 9. 


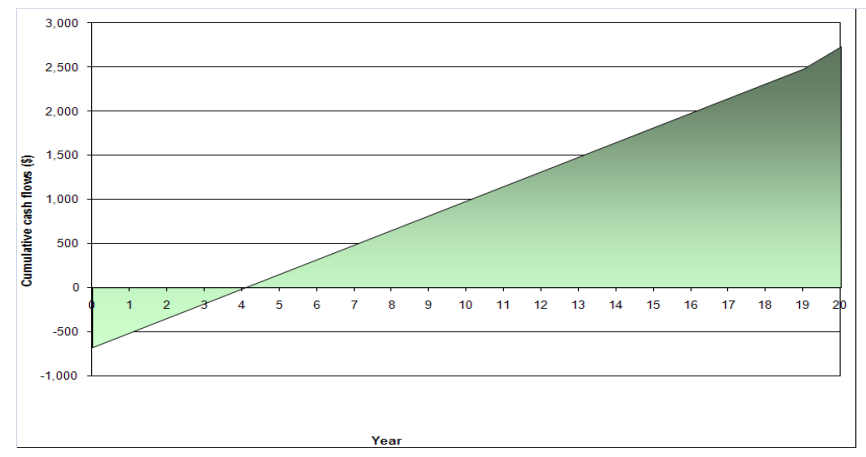

Fig. 9: Payback period of the proposed Solar PV charging System

The analysis estimated that with a capacity factor of $13.8 \%$, the charging system would deliver $7567 \mathrm{Kwh}$ of electricity annually, contributes to $76 \%$ of the EV charging requirements. The remaining $24 \%$ of the charging demand will be fulfilled from the grid. The base case for electricity rates were determined by the maximum monthly $\mathrm{kWh}$ cost of electricity over the last two years, with a $10 \%$ annual addendum with an estimated electricity rate of 13 cents $/ \mathrm{kWh}$ and an annual inflation rate of $2.0 \%$ for the next 20years.It will take approximately four years to start profiting off the design as shown in the cumulative cash flow diagram in figure 9 as payback period.

Though the initial set up cost is high but with the environmental benefits, state incentives, profitable after 4 years, significantly no maintenance cost and provision of the charging power during peak demand time, this would be the best scenario.

\section{Conclusion}

Solar PV charging system is a viable technology with initial cost constraints but profitable in the reasonable payback period. With the constant increase in the power demand, strained transmission and distribution systems and power market deregulation and structuring, the added demand due to the growth of EVs/ PHEVs can easily be addressed through the proposed solar PV based charging set up.The case study for a PHEV/ EV vehicle, very similar to commercially available Chevy Volt and Nissan Leaf depicted favorable results. At peak hours the system can charge the battery to approximately $67 \%$ SOC, enough for daily commute. Also, the proposed strategy contributes to $76 \%$ of the charging demand for the whole year and only $24 \%$ of the charging demand is met through grid. Additionally this $76 \%$ charging demand is met without causing any environmental disturbance. Thus, the overall proposal deemed effective and successful.

\section{References}

[1] M. Shahidehpour, H. Yamin and Z.Y. Li, "Market Operations in Electric Power Systems," John Wiley \&Sons, Inc., New York, 2002.
[2] S.M. Amin, "U.S. grid gets less reliable [The Data],"IEEE Spectrum vol. 48, Issue: 1, 2011.

[3] Escudero-Garzás et al, "Fair Design of Plug-in Electric VehiclesAggregator for V2G Regulation,'IEEE Transactions On Vehicular Technology, vol. 61, no. 8, Oct. 2012 , pp. 3406-3419.

[4] TJ McCue, "Electric-Drive Vehicle Sales Forecast at 3.8 Million

http://evworld.com/news.cfm?newsid=29463 accessed April 2013

[5] J. Paserba, P. Kundur, "Guest editorial - Power grid blackouts remembering and fighting grid failures," IEEE Power and Energy Magazine, vol. 4, Issue: 5, pp. 1621,2006.

[6] S. M. Amin and B. F. Wollenberg, "Toward a smart grid: Power deliveryfor the 21st century," IEEE Power and Energy Magazine, vol. 3, No. 5, pp. 34-4, 2005.

[7] H. Lund, "Large-scale integration of optimal combinations of PV, wind and wave power into the electricity supply," J. of Renewable Energy Vol. 31 ,2006, pp: 503-515.

[8] N. Watrin, R. Roche, H.Ostermann,B. Blunier, and A. Miraoui, "Multi physical Lithium-Based Battery Model for Use in State-of-Charge Determination,'IEEE Transactions on Vehicular Technology, vol. 61, no. 8, Oct. 2012, pp.34203429 .

[9] R. Castro, R. E. Araújo, J. P. F. Trovão, P. G. Pereirinha, P. Melo, and D. Freitas, "Robust DC-Link Control in EVs With MultipleEnergy Storage Systems," IEEE Transactions On Vehicular Technology, vol. 61, no. 8, Oct. 2012, pp. 3553-3565.

[10] GByeon et al, "Energy Management Strategy of the DC Distribution System in Buildings Using the EV Service Model," IEEE Transactions On Power Electronics, vol. 28, no. 4, April 2013, pp.1544-1554.

[11] SAEJ1772, SAE Electric Vehicle and Plug in Hybrid Electric Vehicle Conductive Charge Coupler, published 10/15/2012, Society of Automotive Engineers Standardshttp://standards.sae.org/j1772_201210/accessed April 2013

[12] NIST Special Publication 1108, NIST Framework and Roadmap for Smart Grid Interoperability Standards, Release 1.0* January 2010.

[13] NEC Article 625, A_NEC_625_2008.pdf, National Electric Hand Book, 2008, pp.:971

[14] Level 3 charger -NFPA catlog April 2013

[15] M. Kintner-Meyer,"Smart Charger Technology for Customer Convenience and Grid Reliability", May 2009.

[16] A. Balboul, M. Dughlas, H.A. Chisht, "Interconnection Challenges of Plug-in Hybrid / Electric Vehicles to the Smart Grid," project reported submitted for Hybrid Vehicle Course, Wayne State Univ, May 2010

[17] Gene Liao, “Advance Battery Systems for Hybrid Electric Vehicles" January 2010.

[18] NissanLEAF.pdf, Sept 2011.www.Nissan.com accessed April 2013 
[19] Chvy Volt.pdf, 2012, http://www.chevrolet.com accessed April 2013

[20] Honsberg; Bowden. PVCDROM<http://pvcdrom.pveducation.org/index.html >. accessed April 2013

[21] National solar radiation database $<$ http://rredc.nrel.gov>accessed April 2013

[22] National Climatic Data Center, National Environmental Satellite, Data, and Information Services (NESDIS) [online].accessed April 2013

[23] F. Farret, and M. Simões.Integration of Alternative Sources of Energy. Wiley-IEEE Press, 2006.

[24] T. Tan, "A Model of PV Generation Suitable for Stability Analysis," IEEE Trans.on Energy Conversion, vol. 19, no. 4, pp. 748-755, 2004.

[25] M.S. Alam, and A.T. Alouani, "Dynamic modeling of photovoltaic module for real-time maximum power tracking," J. of Renewable Science and Energy, AIP, NY, vol. 2, no. 3, 2010.

[26] TMS-240PA05Whole Sale Solar. Whole Sale Solar. $<$ http://www.wholesalesolar.com/>.accessed April 2013

[27] Fronius IG Plus 11.1-1 UNi$<$ www.fronius.com/cps/rde/xchg/SID177ECB63.../2714_1483.htm>accessed April 2013

[28] Hybrid Optimization Model for Electric Renewables (HOMER) software package http://www.nrel.gov/homer/accessed April 2013

[29] Experimental Advanced Renewable Program, Consumers Energy: http://www.consumersenergy.com/ content.aspx?id=1801.accessed April 2013

[30] RETSCreen

software $<$ http://www.retscreen.net/ang/home.php $>$ accessed April 2013 